\title{
Angiolymphoid Hyperplasia with Eosinophilia- A Case Report in an Elderly Patient
}

\author{
Bajpai Malay ${ }^{1}$, Rana Deepti ${ }^{2}$ \\ ${ }^{1}$ (department of pathology, hind institute of medical sciences, Safedabad, Barabanki) \\ ${ }^{2}$ (department of dermatology, Max hospital, new delhi.)
}

\begin{abstract}
We describe a 65 year-old man presenting with a scalp nodule of 1 year duration on his left parietal area. The biopsy taken from the lesion, showed increased vascular proliferation, edematous endothelial cells, lymphoid cells and dense eosinophilic infiltrate. The routine and specific blood tests were unremarkable. On the basis of these features, the patient was diagnosed as having angiolymphoid hyperplasia with eosinophilia (ALHE). We present the case because of its rarity in older people, ability to recur; and stress the consideration of ALHE in the differential diagnosis of subcutaneous nodules confined to face and neck.
\end{abstract}

Key words: Angiolymphoid hyperplasia, eosinophilia, scalp nodule

\section{Introduction}

Angiolymphoid hyperplasia with eosinophilia (ALHE) is an uncommon idiopathic condition characterized by isolated or grouped papules, plaques, or nodules in the skin of the head and neck. ALHE is a benign neoplasm, but may be persistent and difficult to eradicate. It presents most commonly in patients aged 20-50 years and rarely in elderly people.

\section{Case History}

A 65 year-old man presented with a scalp nodule of 1 year duration on his left parietal area. His medical history was unremarkable. No abnormality was detected in general physical examination. Dermatological examination revealed an asymptomatic subcutaneous nodule of $2 \times 1 \mathrm{~cm}$ in diameter in the left parietal region of the scalp. Excisional biopsy of the nodule was performed (Figs. 1 and 2).Histopathologic examination of the skin biopsy specimen showed increased vascular proliferation, edematous endothelial cells and perivascular eosinophilic/lymphocytic infiltration. All routine laboratory investigations including whole blood count, sedimentation rate, renal and liver function tests,peripheral blood eosinophil counts were within normal limits. On the basis of clinical and histopathological features, the patient was diagnosed as having ALHE. The patient didn't come to regular follow-up examinations.

\section{Discussion}

Angiolymphoid hyperplasia with eosinophilia, first described by Wells and Whimster in 1969, is a rare benign vascular tumor.[1] It is characterized by one or more purplish, brownish papules and subcutaneous nodules with a predilection for the head and neck regions. Other tissues such as orbit, heart, bone, liver and spleen may also be involved. It is more common in middle-aged females. Contrary the name suggests, peripheral blood eosinophilia is not a constant finding in ALHE.[2] Histopathologically, ALHE is characterized by numerous thick and thin-walled vessels lined with characteristic edematous endothelial cells ("hobnail"or "tombstone" appearance) associated with variable lymphocytic and eosinophilic infi ltrate. [3]

The etiopathogenesis of ALHE is not well known. Trauma, hormonal changes and infections (HTLV or HHV 8) have been suggested to play a role in the pathogenesis. Association of ALHE with nephritic syndrome and pregnancy have been described.[4,5] Overexpression of estrogen and progesterone receptors was detected in pregnant women.[6]Interleukin 5 and vascular endothelial growth factor were also found to be increased in some cases.[7 ]The subcutaneous lesions associated with ALHE may vary in colour, shape and size. Ranging from red to brown in colour, the lesions may be smooth or centrally eroded with crusting. The size of a single lesion may vary from 0.2 to $8 \mathrm{~cm}$, most commonly measuring $0.5-2 \mathrm{~cm}$. Approximately $80 \%$ of patients demonstrate solitary lesions, while $20 \%$ have multiple lesions clustered in one area. They are most commonly seen in the peri-auricular area, forehead or scalp. Rare sites of involvement include the shoulders, hands,breasts and penis. ALHE tends to affect the skin and subcutaneous tissues, however, it has also been described in other tissues, such as the orbit, oral mucosa, liver, spleen, heart, bone and blood vessels.[8] Systemic eosinophilia of $6-34 \%$ is seen in $20 \%$ of patients. [9] Regional lymphadenopathy and arteriovenous shunts have occasionally been reported but are inconsistent features. Since they share many clinical and histopathological similarities, ALHE should be differentiated from Kimura's disease. Kimura's disease occurs in younger patients, the lesions show deeper localization and association with lymphadenopathy. Histologically, it contains sclerosis at any 
stage, but does not have epithelioid endothelial cells. ALHE rarely regresses spontaneously; however, malignant transformation does not occur. Several treatment modalities have been used, including intralesional corticosteroid injections, interferon $\alpha 2 \mathrm{~b}$, cytotoxic agents,cryotherapy, electrodessication, pulse-dye laser and carbon dioxide laser. Surgical excisions that include the arterial and venous segments at the base of the lesion are most successful, with no reported recurrence after 1 year of

follow-up. [10]

\section{References}

[1] Wells GC, Whimster IW. Subcutaneous angiolymphoid hyperplasia with eosinophilia. Br J Dermatol 1969;81:1-14

[2] Zarrin-Khameh N, Spoden JE, Tran RM. Angiolymphoid hyperplasia with eosinophilia associated with pregnancy: A case report and review of the literature. Arch Pathol Lab Med 2005;129:1168-71.

[3] Olsen TG, Helwig EB. Angiolymphoid hyperplasia with eosinophilia: A clinicopathologic study of 116 patients. J Am Acad Dermatol 1985; 12:781-96.

[4] Hollo P, Marschalko M, Sikos G, Harsing J, Horvath A.Angiolymphoid hyperplasia with eosinophilia in pregnancy. J Eur Acad Dermatol Venereol 2005;19:645-6.

[5] Azizzadeh M, Namazi MR, Dastghaib L, Sari-Aslani F. Angiolymphoid hyperplasia with eosinophilia and nephritic syndrome. Int J Dermatol 2005;44:242-4

[6] Moy RL, Luftman DB, Nguyen QH, Amenta JS. Estrogenreceptors and the response to sex hormones in angiolymphoid hyperplasia with eosinophilia. Arch Dermatol 1992;128:825-8.

[7] Aoki M, Kimura Y, Kusunoki T, Tahara S, Kawanah S.Angiolymphoid hyperplasia with eosinophilia associated with anomalous dilation of occipital artery: IL-5 and VEGF expression of lesional mast cells. Arch Dermatol 2002;138:982-4

[8] Moran WJ, Dobleman TJ, Bostwick DG. Epithelioid hemangioendothelioma (histiocytoid hemangioma) of the palate. Laryngoscope 1987 ; 97 : 1299 - 302

[9] Olsen TG, Helwig EB . Angiolymphoid hyperplasia with eosinophilia. A clinicopathologic study of 116 patients. $J$ Am Acad Dermatol 1985 ; 12 ( 5 Pt 1 ): 781 - 96.

[10] Baum EW, Sams WM Jr, Monheit GD . Angiolymphoid hyperplasia with eosinophilia. The disease and a comparison of treatment modalities. J Dermatol Surg Oncol $1982 ; 8$ : 966 - 70

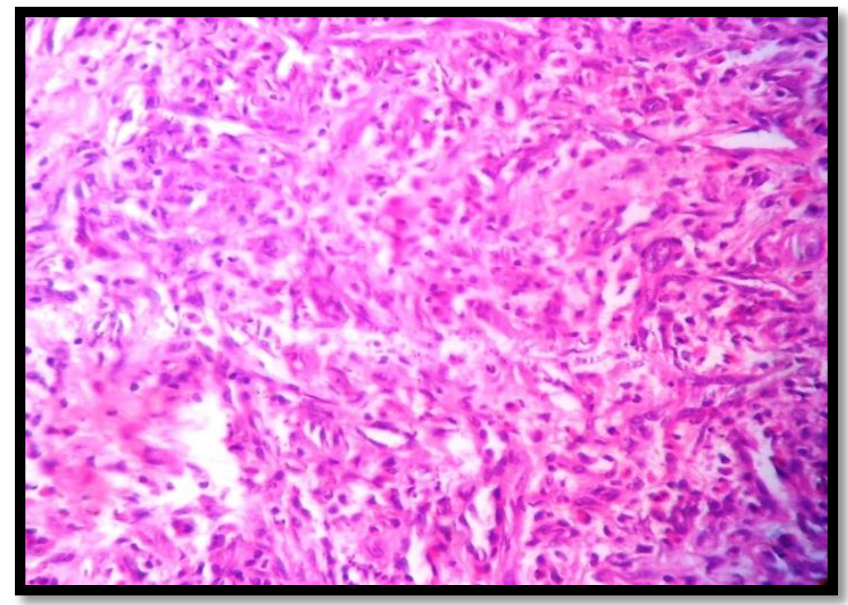

Figure 1 : prominent eosinophilic infiltrate and endothelial cells $(\mathrm{H} \& \mathrm{E}, \mathrm{x} 40)$

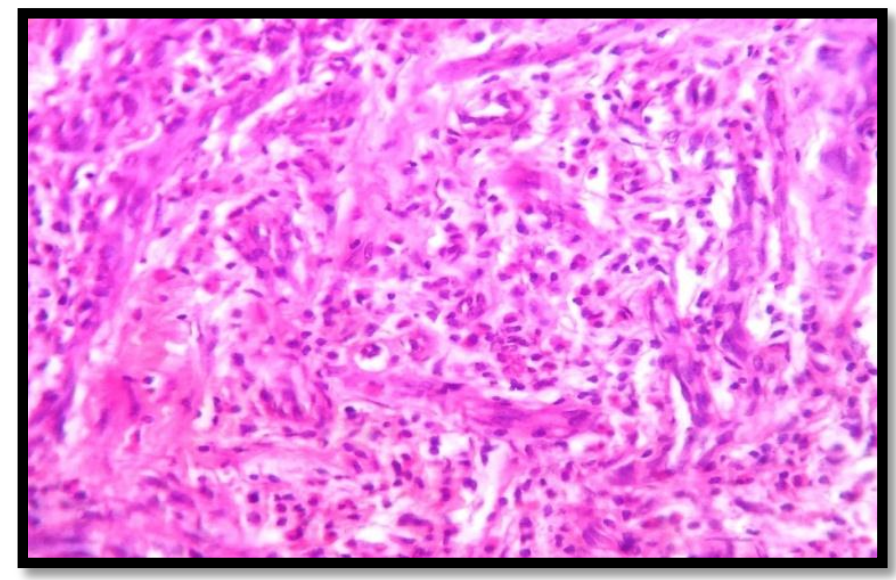

Figure 2 : prominent eosinophilic infiltrate and endothelial cells(H\&E ,x40) 